\title{
QUALIDADE MICROBIOLÓGICA DA ÁGUA UTILIZADA EM PROPRIEDADES LEITEIRAS
}

\author{
Microbiological quality of used water in dairy farms
}

\author{
Adriano Henrique do Nascimento Rangel ${ }^{l}$, Rayssa Maria Bezerril Freire ${ }^{l}$, \\ Luís Henrique Fernandes Borba ${ }^{1}$, Dorgival Morais de Lima Júnior ${ }^{2 *}$, \\ Luciano Patto Novaes ${ }^{l}$
}

\begin{abstract}
RESUMO
Objetivou-se avaliar a qualidade microbiológica de amostras de água de poço utilizada na ordenha, além de verificar sua influência na contagem bacteriana total (CBT) do leite obtido em propriedades no estado do Rio Grande do Norte. Amostras de $1.000 \mathrm{~mL}$ de água do poço e da água utilizada na ordenha foram coletadas em recipientes estéreis e realizadas análises de coliformes totais e termotolerantes, pelo método de membrana filtrante. Amostras da água do poço apresentaram valores de $21.250 \mathrm{UFC} / 100 \mathrm{~mL}$ para coliformes totais e $12.269 \mathrm{UFC} / 100 \mathrm{~mL}$ para coliformes termotolerantes e as amostras da água da ordenha apresentaram valores de $5.520 \mathrm{UFC} / 100 \mathrm{~mL}$ para coliformes totais e $3.483 \mathrm{UFC} / 100 \mathrm{~mL}$ para coliformes termotolerantes. A detecção de coliformes nas amostras analisadas afetou a qualidade microbiológica do leite avaliada por meio da CBT. Constatou-se que a qualidade microbiológica da água utilizada nas propriedades leiteiras apresenta-se fora do preconizado pelo Ministério da Saúde para uso na higienização dos equipamentos e consumo pelos animais e seres humanos, quanto aos padrões de potabilidade.
\end{abstract}

Palavras-chave: água na pecuária; coliformes totais; coliformes termotolerantes; qualidade de água.

1 Universidade Federal do Rio Grande do Norte (UFRN), Programa de Pós-graduação em Produção Animal, Macaíba, RN, Brasil.

2 Universidade Federal de Alagoas (UFAL), Campus Arapiraca, Av. Manoel Severino Barbosa, s/n, Bom Sucesso, 57309-005, Arapiraca, AL, Brasil. E-mail: juniorzootec@yahoo.com.br

* Autor para correspondência. 


\begin{abstract}
The objective of this study was to characterize the microbiological quality of well water samples and used in milking besides verifying its influence on milk total bacterial count (CBT) of dairy farms in the state of Rio Grande do Norte. Samples of $1.000 \mathrm{~mL}$ of water directly from the well and also from the water used in the milking routine were collected in sterile containers and analyses were performed for total coliforms and thermo tolerant coliforms using the membrane filter method. The water from the well had 21,250 CFU/100 mL for total coliforms and 12,269 CFU/100 mL thermo tolerant coliforms whereas the water used im milking procedures showed lower values, 5,520 CFU/100 mL for total coliforms and 3,483 CFU / $100 \mathrm{~mL}$ for thermo tolerant coliforms. The detection of coliforms in samples affected the microbiological quality of milk evaluated by CBT. It was found that the microbiological quality of water used in dairy farms is presented outside the recommended by the Ministry of Health for use in cleaning of equipment and consumption by animals and humans, as the potability standards.
\end{abstract}

Keywords: water for livestock; total coliforms; thermotolerant coliforms; water quality.

\section{INTRODUÇÃO}

A água é considerada um dos elementos fundamentais para a existência do homem. Sua utilização no abastecimento público, industrial e agropecuário, na preservação da vida aquática, na recreação e no transporte demonstra essa importância vital (GUILHERME et al., 2000). Além disso, é indispensável na manutenção da vida no planeta, e desperta o interesse de diversos setores. Em virtude de sua intensa utilização nas propriedades leiteiras constituise em expressiva fonte de veiculação de microrganismos no leite, pois além de servir para o consumo dos animais, seu uso é fundamental em atividades relacionadas à ordenha e sanidade do rebanho (GUERRA et al., 2011; KHELIL-ARFA et al., 2012). Sendo necessários trabalhos de orientação, treinamento e conscientização quanto a sua melhor utilização.

Os parâmetros utilizados como critério de qualidade da água são os aspectos físicos, químicos e microbiológicos. As análises físicas medem e indicam características perceptíveis pelos sentidos, que incluem a cor, turbidez, odor e sabor. Os aspectos químicos da água são resultantes da presença de substâncias dissolvidas, em geral avaliáveis somente por meios analíticos, como a dure$\mathrm{za}$, acidez, $\mathrm{pH}$, alcalinidade, cloretos e cloro residual, que comprometem a limpeza e desinfecção dos equipamentos e utensílios. Quanto à qualidade microbiológica, a água pode atuar como veículo carreador de microrganismos patogênicos e deterioradores, e constitui-se em risco à qualidade do alimento e à saúde do consumidor (BRAMLEY, 1992; CERQUEIRA et al., 2007; RAMIRES et al., 2009; SILVA et al., 2011).

Segundo Ribeiro et al. (2000), a água utilizada no ambiente de ordenha para limpeza, tanto dos tetos dos animais como dos equipamentos de ordenha (coletores, ordenhadeiras mecânicas e baldes), pode atuar como via de transmissão de microrganismos para a glândula mamária, bem como comprometer a qualidade do leite, uma vez que a água com alta contagem de bactérias, utilizada 
na limpeza dos equipamentos, possibilita a veiculação da população bacteriana diretamente para o leite quando este entra em contato com as superfícies contaminadas. Isto é especialmente importante no que se refere à contagem bacteriana total (CBT), o que inviabiliza a obtenção de alimentos que atendam aos padrões exigidos pela legislação (LEITE et al., 2003; LACERDA et al., 2009; GUERRA et al., 2011; BRANDÃO et al., 2013).

De acordo com a Instrução Normativa 62 (BRASIL, 2011), análises de composição (teores de gordura, proteína e sólidos totais), contagem bacteriana total (CBT), contagem de células somáticas (CCS) e resíduos de drogas veterinárias de todo leite cru produzido no país e processado em estabelecimentos sob fiscalização federal deverão ser realizadas mensalmente em laboratórios credenciados pelo Ministério da Agricultura, Pecuária e Abastecimento-MAPA. As condições de estocagem e resfriamento do leite, a presença de resíduos de medicamentos ou produtos químicos e a qualidade microbiológica da água podem interferir nos valores encontrados de CBT em amostras de leite. Por isso, a qualidade da água utilizada durante toda cadeia produtiva do leite, desde a ordenha do animal até a limpeza e sanitização dos utensílios e equipamentos, exerce papel fundamental no resultado final da qualidade e segurança dos produtos lácteos.

A Portaria $n^{0} 2.914$ do Ministério da Saúde (ANVISA, 2011) determina que a água de qualquer origem, para ser considerada potável, deve ser isenta de coliformes termotolerantes. Isso indica que são necessárias análises químicas e microbiológicas periódicas para comprovar a potabilidade da água e, consequentemente, utilizá-la na ordenha. A qualidade microbiológica da água também pode afetar a qualidade do leite, elevando, principalmente, a Contagem Bacteriana Total (CBT), inviabilizando, assim, a obtenção de alimentos que atendam aos padrões microbianos exigidos pela legislação vigente.

É fundamental que o produtor de leite tenha conhecimento dos padrões microbiológicos da água utilizada na ordenha, como para o consumo animal. O presente estudo objetivou avaliar a qualidade microbiológica de amostras de água de poço e utilizada na ordenha além de verificar sua influência na contagem bacteriana total (CBT) de amostras de leite em propriedades no estado do Rio Grande do Norte.

\section{MATERIAL E MÉTODOS}

O experimento foi conduzido em cinco propriedades leiteiras comerciais, no período de janeiro a setembro de 2011, na região Agreste do Estado do Rio Grande do Norte. A região é caracterizada, por um clima tropical chuvoso com época seca e chuvosa bem definida. A época chuvosa compreende o período de abril a junho com precipitação pluviométrica média de $855 \mathrm{~mm}$ ao ano. A temperatura média é $25,3{ }^{\circ} \mathrm{C}$ e a umidade relativa média de 79,0\% (IDEMA, 2011).

Em cada propriedade, realizou-se um levantamento dos dados por meio da aplicação de um questionário para caracterização e diagnóstico da atual situação do sistema de produção. Os itens contemplados foram sistema de alimentação, composição racial do rebanho, número de vacas ordenhadas, número de ordenhas diárias, produtividade (L/vaca/dia), produção total de leite (L/propriedade/dia), composição, contagem de célula somática e contagem bacteriana total do leite em laboratórios da Rede Brasileira de Qualidade do Leite (RBQL).

$\mathrm{O}$ procedimento de coleta do leite realizou-se após a homogeneização por meio de agitação mecânica, e posteriormente retiradas do tanque de refrigeração com o auxílio de uma concha de aço inoxidável higienizada. As amostras de leite foram acondicionadas 
em frascos plásticos de $40 \mathrm{~mL}$, contendo o conservante químico azidiol e enviadas para um laboratório integrante da Rede Brasileira de Qualidade do Leite em Piracicaba (SP). As análises da contagem bacteriana total (CBT) foram realizadas pelo método de citometria de fluxo por meio da utilização do equipamento Bactocount 150 (Bentley Instruments Inc., Chasca, MN, EUA) e os resultados foram expressos em número de unidades formadoras de colônia/mL de leite (UFC/mL).

A coleta de amostras de água dos poços e a utilizada nas ordenhas de cada propriedade foi realizada no mês de julho de 2011. Foram coletadas assepticamente em frascos esterilizados com capacidade de $1000 \mathrm{~mL}$, acondicionadas em caixa de material isotérmico e posteriormente enviadas ao laboratório de qualidade de água da Empresa de Pesquisa Agropecuária do Rio Grande do Norte (EMPARN), para realização das análises de dureza e microbiológicas.

As amostras foram avaliadas pelo método da membrana filtrante (APHA et al., 2012). Os parâmetros avaliados foram número de coliformes totais e termotolerantes (Tabela 1).

Os dados obtidos foram analisados por meio da estatística descritiva pelo proce- dimento MEANS do Statistical Analyses System (SAS, 2002), na avaliação das médias, para a análise de água considerou-se os limites da legislação brasileira em vigor foram classificadas de acordo com os valores médios para cada parâmetro.

\section{RESULTADOS E DISCUSSÃO}

A maioria $(80 \%)$ das propriedades avaliadas utilizavam o sistema de semiconfinamento (Tabela 2) com animais holandêszebu de diferentes composições genéticas, com média de 134 vacas/ordenhadas, duas vezes ao dia, com produção de 13,66 L/vaca/ dia. Apenas $25 \%$ das propriedades avaliadas realizavam controle da qualidade do leite em laboratórios da Rede Brasileira de Qualidade do Leite (RBQL), quando da aplicação do questionário.

Em relação à dureza da água de poço, observou-se média de 44,51 $\mathrm{mg} \mathrm{CaCO}_{3} / \mathrm{L}$, evidenciando água mole (RICHTER; AZEVEDO NETO, 1991).

Os resultados das análises de água apresentaram valores elevados para coliformes (Tabela 3), estando assim fora dos padrões de potabilidade descrito na Portaria $\mathrm{n}^{\circ} 2.914$, de 12 de dezembro de 2011 (ANVISA 2011).

Tabela 1 - Padrão das características microbiológicas da água

\begin{tabular}{|c|c|c|c|}
\hline \multirow{2}{*}{ Classe } & \multicolumn{2}{|c|}{ Características Microbiológicas } & \multirow{2}{*}{ Utilização } \\
\hline & Coliformes Totais & C. Termotolerantes & \\
\hline 1 & $<1$ & $<1$ & Potável \\
\hline 2 & $\leq 5.000$ & $\leq 1.000$ & $\begin{array}{l}\text { Recreação, irrigação } \\
\text { (frutas, hortaliças). }\end{array}$ \\
\hline 3 & $\leq 20.000$ & $\leq 4.000$ & $\begin{array}{c}\text { Pesca, } \\
\text { consumo animal. }\end{array}$ \\
\hline 4 & $>20.000$ & $>4.000$ & $\begin{array}{l}\text { Navegação, indústria, } \\
\text { irrigação de grandes culturas. }\end{array}$ \\
\hline
\end{tabular}

Fonte: ANVISA (2011) 
Tabela 2 - Dados de manejo dos rebanhos avaliados pelo Sistema de Alimentação (SA), Composição Racial do Rebanho (CRR), Número de Vacas Ordenhadas (NVO), Número de Ordenhas Diárias (NOD), Produtividade (L/vaca/dia) (P), Produção Total de Leite (L/prop./ dia) (PTL), Controle da Qualidade do Leite (CQL) e Dureza da água (DA) $\left(\mathrm{mg} \mathrm{CaCO}_{3} / \mathrm{L}\right)$ das 5 propriedades estudadas

\begin{tabular}{|c|c|c|c|c|c|c|c|c|}
\hline Propriedade & $\mathrm{SA}^{*}$ & CRR & NVO & NOD & $\mathrm{P}$ & PTL & CQL & DA \\
\hline A & $\mathrm{SC}$ & Girolando $3 / 4$ & 105 & 2 & 11,43 & 1.200 & Não & 31,63 \\
\hline B & $\mathrm{SC}$ & $\begin{array}{l}\text { 3/4 Girolando } \\
e^{7 / 8} \text { Holandês }\end{array}$ & 166 & 2 & 11,75 & 1.950 & Sim & 116,00 \\
\hline $\mathrm{C}$ & $\mathrm{SC}$ & 3/4 Girolando & 177 & 2 & 11,86 & 2.100 & Sim & 39,96 \\
\hline $\mathrm{D}$ & $\mathrm{SC}$ & Jersey P.O & 48 & 2 & 15,00 & 720 & Não & 6,66 \\
\hline $\mathrm{E}$ & $\mathrm{C}$ & Holandês PC & 281 & 3 & 17,89 & 5.026 & Não & 28,30 \\
\hline
\end{tabular}

* Confinado e Semiconfinado

Tabela 3 - Médias dos valores de coliformes totais (UFC/ $100 \mathrm{~mL})(\mathrm{CTO})$ e coliformes termotolerantes (UFC/ $100 \mathrm{~mL}$ ) (CTT) de amostras de água do poço e utilizada na ordenha.

\begin{tabular}{ccc}
\hline & \multicolumn{2}{c}{ CaracterísticasMicrobiológicas } \\
\hline Variáveis & CTO & CTT \\
& $(\mathrm{UFC} / 100 \mathrm{~mL})$ & $(\mathrm{UFC} / 100 \mathrm{~mL})$ \\
\hline Poço & $21.250^{\mathrm{a}}$ & $12.269^{\mathrm{a}}$ \\
Ordenha & $5.520^{\mathrm{a}}$ & $3.484^{\mathrm{a}}$ \\
\hline
\end{tabular}

As variáveis estudadas mostraram que a água de poço e a utilizada na ordenha não se apresentaram dentro dos padrões de potabilidade, ou seja, impróprias para o consumo humano. Quanto a sua classificação, recomendou-se a utilização da água de poço para irrigação de grandes culturas e a água de ordenha para o consumo animal (Tabela 1).

Os resultados obtidos no presente estudo foram similares aos verificados por Rapini et al. (2003) em propriedades leiteiras da região metropolitana de Belo Horizonte-MG, onde $76,8 \%$ e $60,9 \%$ da água utilizada na limpeza de equipamentos e utensílios de ordenha apresentavam coliformes totais e coliformes termotolerantes, respectivamente, por isso a preocupação com a qualidade da água utilizada no processo de ordenha deve ser constante. Medeiros (2005) analisou a água utilizada na ordenha, limpeza dos tetos e ordenhadeiras, em propriedades leiteiras no Município de Cerqueira César-SP e concluiu que $94 \%$ das amostras de água estavam fora dos padrões de potabilidade. Ainda corroborando com este estudo, Lamas (2014) evidenciaram que as amostras de água utilizadas na limpeza dos tanques de expansão estavam fora dos padrões da legislação brasileira (ANVISA, 2011).

Observou-se que a qualidade microbiológica da água utilizada no processo de higienização de equipamentos de ordenha afetou a contagem bacteriana total do leite (CBT). Houve aumento na CBT em função de valores mais elevados da característica microbiológica da água (Figura 1), todavia houve uma redução nos valores médios de CBT no decorrer dos meses avaliados, o que demostra que o monitoramento por meio da análise de água contribuiu para uma melhoria desse parâmetro.

Em Minas Gerais, Araújo et al. (2011) constataram valores de CBT mais elevados em amostras de leite das propriedades que 


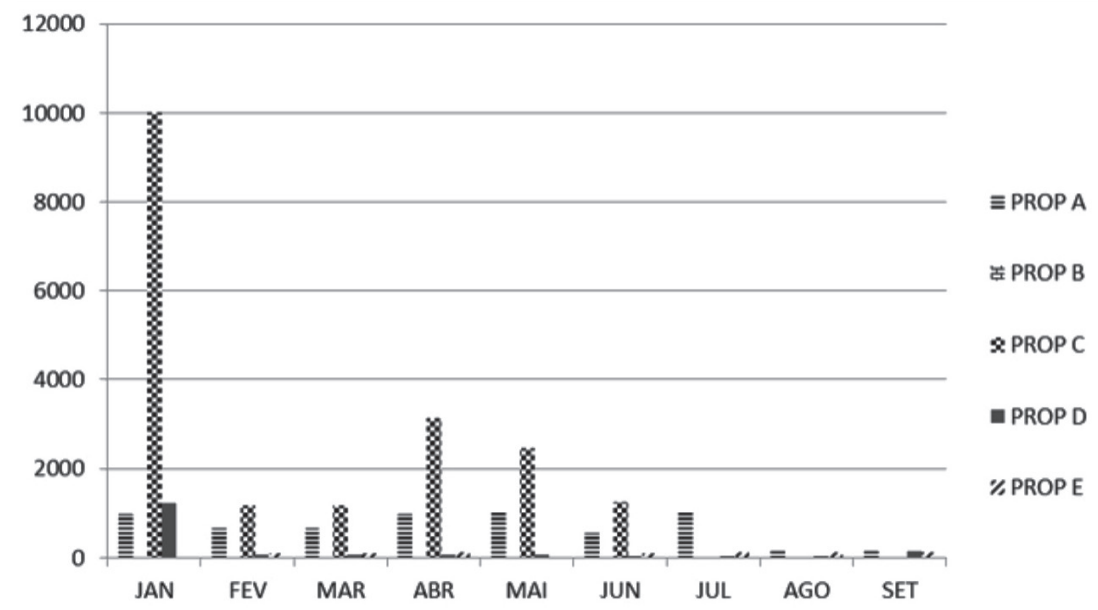

Figura 1 - Média de CBT obtida de amostras de leite coletadas em cinco propriedades leiteiras avaliadas no período de janeiro a setembro de 2011

utilizavam água com níveis mais altos de contaminação. Entretanto, Ramires (2007), na região de Curitiba/PR, não verificou influência da qualidade microbiológica da água em relação à qualidade do leite, apesar de identificar sérios problemas na qualidade microbiológica da água. Não foi verificada influência da presença ou ausência de coliformes a $45{ }^{\circ} \mathrm{C}$ em valores de CBT do leite $(\mathrm{p}>0,05)$, assim como dos atributos químicos da água ( $\mathrm{pH}$ e dureza).

A dureza da água pode interferir nos valores de CBT, devido à falta de eficiência dos detergentes na higienização dos equipamentos, este efeito passa a ser importante quando a concentração de carbonato de cálcio ultrapassa $100 \mathrm{mg} / \mathrm{mL}$ (LAGGER et al., 2000; AMARAL et al., 2004; SILVA et al., 2011), o que não foi o caso, na maioria das amostras de água coletadas e analisadas neste trabalho (Tabela 2). João et al. (2011) também não observaram influencia da dureza da água sobre os parâmetros microbiológicos da água em propriedades leiteiras no meio oeste catarinense.

\section{CONCLUSÕES}

A qualidade microbiológica da água utilizada nas propriedades leiteiras estudadas está em desacordo com o preconizado pelo Ministério da Saúde para uso na higienização dos equipamentos e consumo pelos animais e seres humanos e pode tornar-se veículo carreador de microrganismos indesejáveis e afetar a qualidade microbiológica do leite.

\section{REFERÊNCIAS}

AGÊNCIA NACIONAL DE VIGILÂNCIA SANITÁRIA (ANVISA). Portaria n 2.914 , de 12 de dezembro de 2011. Dispõe sobre os procedimentos de controle e de vigilância da qualidade da água para consumo humano e seu padrão de potabilidade. Diário Oficial da República Federativa do Brasil, Brasília, 14 dez. 2011. Seção 1, p. 39.

AMARAL L. A. et al. Qualidade da água em propriedades leiteiras como fator de risco a qualidade do leite e a saúde da glândula 
mamária. Arquivo do Instituto Biológico, v. 74, n. 4, p. 417-421, 2004.

AMERICAN PUBLIC HEALTH ASSOCIATION (APHA); AMERICAN WATER WORKS ASSOCIATION (AWWA); WATER ENVIRONMENT FEDERATION (WEF). Standard methods for the examinationof water and wastewater. $22^{\text {nd }} \mathrm{ed}$. Washington: American Water Works Assn, 2012. 1496p.

ARAÚJO, M. M. P. et al. Qualidade higiênicosanitária do leite e da água de algumas propriedades da bacia leiteira do município de Luz-MG. Revista de Biologia e Ciências da Terra, v. 9, n. 2, p. 154-171, 2009.

BRAMLEY, A. J. Milking hygiene and mastitis control. In: VAN HORN, H. H.; WILCOX C. J. (eds.) Large dairy herd management. Champaign: American Dairy Science Association, 1992. p.457-463.

BRANDÃO, V. I. et al. Qualidade do leite produzido no município de Rio Pomba, MG, com base em aspectos regulatórios. Perspectivas online, v. 9, n. 3, p. 46-55, 2013.

BRASIL. Ministério da Agricultura, Pecuária e Abastecimento. Instrução Normativa $\mathrm{n}^{\text {o }}$ 62, de 29 de dezembro de 2011. Aprova o Regulamento Técnico de Produção, Identidade e Qualidade do Leite tipo A, o Regulamento Técnico de Identidade e Qualidade de Leite Cru Refrigerado, o Regulamento Técnico de Identidade e Qualidade de Leite Pasteurizado e o Regulamento Técnico da Coleta de Leite Cru Refrigerado e seu Transporte a Granel, em conformidade com os Anexos desta Instrução Normativa. Diário Oficial da República Federativa do Brasil, Brasília, 30 dez. 2011. Seção 1, p. 6.

CERQUEIRA, M. M. O. P.; SOUZA, M. R.; SENA, M. J. Qualidade da água e seu impacto na qualidade microbiológica do leite.
Revista Leite Integral, v. 7, p. 54-61, fev./ mar. 2007.

GUERRA, M. G. et al. Disponibilidade e qualidade da água na produção de leite. Acta Veterinaria Brasilica, v. 5, n. 3, p. 230-235, 2011.

GUILHERME, E. F. M.; SILVA, J. A. M.; OTTO, S. S. Pseudomonas aeruginosa como indicador de contaminação hídrica. Higiene Alimentar, v. 14, n. 76, p. 43-46, 2000.

INSTITUTO DE DESENVOLVIMENTO SUSTENTÁVEL E MEIO AMBIENTE (IDEMA). 2011. Disponível em: <http://www. idema.rn.gov.br>. Acesso em: 02 out. 2014.

JOÃO, J. H. et al. Qualidade da água utilizada na ordenha de propriedades leiteiras do Meio Oeste Catarinense, Brasil. Revista de Ciências Agroveterinárias, v. 10, n. 1, p. 9-15, 2011.

KHELIL-ARFA, H. et al. Prediction of water intake and excretion flows in Holstein dairy cows under thermoneutral conditions. Journal of Animal Biosciences, v. 6, n. 10, p. 1662-1676, 2012.

LACERDA, L. M; MOTAR, A.; SENA, M. J. Qualidade microbiológica da água utilizada em fazendas leiteiras para limpeza das tetas de vacas e equipamentos leiteiros em três municípios do Estado do Maranhão. Arquivos do Instituto Biológico, v. 76, n. 4, p. 569575, 2009.

LAGGER, J. R. et al. La importancia de la calidad del água em producción lechera. Veterinary Argentina, v. 27, n. 165, p. 346354, 2000.

LAMAS, J. M. N. Qualidade da água utilizada na limpeza dos tanques de granelização de leite cru: implantação e avaliação da 
cloração da água para garantia da qualidade do produto. 102f. 2014. Dissertação (Mestrado em Ciência e Tecnologia de Leite e Derivados) - Universidade Federal de Juiz de Fora, Juiz de Fora, 2014.

LEITE, M. O. et al. Controle de qualidade da água em indústrias de alimentos. Revista Leite \& Derivados, v. 69, p. 38-45, mar. 2003.

MEDEIROS, M. I. M. Associação de agentes patogênicos isolados em análise microbiológica da água, com a presença de mastite clínica ou subclínica, em propriedades leiteiras da região de Cerqueira César-SP. 2005. 73f. Dissertação (Mestrado em Medicina Veterinária) - Universidade Estadual Paulista, Botucatu, 2005.

RAMIRES, C. L. A influência da qualidade microbiológica da água na qualidade do leite. 2007. 70f. Monografia (Graduação em Zootecnia) - Universidade Federal do Paraná, Curitiba, 2007.

RAMIRES, C. H.; BERGER, E. L.; ALMEIDA, R. Influência da qualidade microbiológica da água sobre a qualidade do leite. Archives of Veterinary Science, v. 14, n. 1, p. 36-42, 2009.

RAPINI, L. S. et al. Qualidade microbiológica da água de propriedades leiteiras na região metropolitana de Belo Horizonte - MG. Revista Instituto Laticínios Cândido Tostes, v. 58, n. 333, p. 95-98, 2003.

RIBEIRO, A. R. et al. Análise microbiológica da qualidade da água utilizada na ordenha em propriedades leiteiras do Estado de São Paulo e Minas Gerais. Napgama, v. 3, n. 3, p. 3-6, 2000.

RICHTER, C. A.; AZEVEDO NETTO, J. M. Tratamento de Água. Tecnologia Atualizada. São Paulo, Edgard Blücher, 1991. $332 \mathrm{p}$.

SILVA, L. C. C. et al. Rastreamento de fontes da contaminação microbiológica do leite cru durante a ordenha em propriedades leiteiras do Agreste Pernambucano. Semina: Ciências Agrárias, v. 32, n. 1, p. 267-276, 2011. 